\title{
Muslim Adolescent Mental Health in Australia: A Cross-Cultural Comparison of the Risk of Developing Clinically Significant Psychological Problems
}

\author{
Rony Kayrouz $\mathbb{B}^{1,2} \cdot$ Eyal Karin ${ }^{2} \cdot$ Carawan $_{\text {Ghanem }}^{3} \cdot$ Nafisa Choudhury $^{3} \cdot$ Ahmad Malas $^{3}$
}

Accepted: 25 January 2022 / Published online: 19 February 2022

(c) The Author(s) 2022

\begin{abstract}
This study explores the risk of developing clinically significant social, emotional, and behavioural problems among Muslim adolescents living in Australia compared to the general adolescent population living in Australia. A descriptive, cross-sectional, and exploratory survey of 12-17-year-old students across three Islamic schools in New South Wales was conducted. The Strengths and Difficulties Questionnaire (SDQ) was used to measure the risk of developing clinically significant social, emotional, and behavioural problems. Six hundred and thirty-two students (261 males, 371 females), at a response rate of 48\%, were recruited via collaborations with three Islamic schools, and children were invited to participate if their parents did not object in writing to their child's participation. Overall, when compared to the general adolescent community sample, Muslim adolescents did not report a significantly higher proportion in the top $10 \%$ (i.e., abnormal range) for total difficulties, emotional problems, conduct problems, and peer problems, but did report a significant difference for hyperactivity/inattention problems (18.4\% vs. 13.8\%). Furthermore, Muslim adolescents (29.0\% vs. $23.7 \%$ ) reported a significantly higher proportion of scores in the top $20 \%$ (i.e., borderline range). These differences were explained by Muslim females aged 11-15 years higher hyperactivity $(15.1 \%$ vs. $11.4 \%)$ and total difficulties (31.8\% vs. $24 \%$ ), as younger males and older males and older females showed no difference on any scale. Specifically, Muslim females aged 11-15 years reported a significantly higher proportion of scores in the abnormal ranges for total difficulties (14.3\% vs. 9.8\%), emotional problems (17.6\% vs. $12.6 \%)$, and conduct problems (11.2\% vs. $7.5 \%$ ) and marginally for hyperactivity. Muslim females aged 11-15 years may demonstrate higher rates of clinically significant problems and are at a substantial higher risk of developing clinically significant emotional and conduct problems when compared to their age-related female adolescent peers. A review of the current child and adolescent mental health and community services is required to determine if this risk to Muslim females aged 11-15 years in Australia is being mitigated and their needs are being met.
\end{abstract}

Keywords Australia $\cdot$ Muslim youth $\cdot$ Adolescent $\cdot$ Mental health $\cdot$ School

\section{Highlights}

- The study explored the substantial risk of Muslim adolescents in Australia developing clinically significant social, emotional, and behavioural problems compared to the general adolescent population.

- Socioeconomic status was a significant predictor of scores but was controlled in the analyses.

- Muslim males (11-17 years) and older Muslim females (16-17 years) are not at higher substantial risk of developing clinically significant social, emotional, and behavioural problems compared to the general adolescent population.

- Muslim females (11-15 years) are at a substantially higher risk of developing clinically significant emotional and conduct problems than age-related females.

- Muslim females (11-17 years) were at even greater risk of developing clinically significant conduct problems, emotional symptoms, and hyperactivity-inattention problems than Muslim males (11-17 years).

Rony Kayrouz

rony.kayrouz@mq.edu.au

1 Psychodos, Marrickville, NSW, Australia
2 Department of Psychology, Macquarie University, Sydney, NSW, Australia

3 Lebanese Muslim Association, Lakemba, NSW, Australia 
- A review of current community and outreach services is required to assess if the psychological needs of Muslim youth in Australia, particularly females aged 11-15 years, are being met.

Adolescence is a crucial period where many mental health disorders may develop (Paus et al., 2008). Thus, mitigating risk and promoting protective factors associated with mental disorders in childhood/adolescence is critical to ensure that children and adolescents grow to be well-adjusted and resilient adults. A review of the meta-analyses of risk and protective factors associated with mental health disorders with onset in childhood/adolescence found that most factors were biological, and no convincing evidence of the few systemic or psychosocial risk or protective factors investigated (Kim et al., 2020; Kim et al., 2019; Solmi et al., 2021). The review highlighted that systemic and psychosocial risk and protective factors were under-researched.

However, despite this gap, racial discrimination is a risk factor, and ethnic identity is a protective factor associated with adverse mental health outcomes. A systematic review found that discrimination was associated with anxiety, depression, and negative self-esteem in adolescents living in several developed countries, including Australia (Priest et al., 2013). In addition, a longitudinal study found that perceived racism was associated with later suicide and suicidal ideation (Walker et al., 2017). In contrast, ethnic identity was a protective factor in mitigating suicide risk when other acculturative stressors occur (Cheref et al., 2019; Walker et al., 2008). These findings highlight the complex interplay of risk and protective factors that need to be considered when evaluating the mental health outcomes of adolescent populations.

One such adolescent population that has been subject to racial and religious discrimination is the Muslim youth living in Australia. About 600,000 Muslims live in Australia, with $66 \%$ under 35 years of age (Australian Bureau of Statistics, 2016). Australian research on Muslim Youth spanning over 30 years identified several risk factors for poor mental health outcomes. Young Muslim Australians reported experiencing racial discrimination, vilification, higher unemployment, and poverty, and their identity was negatively impacted by the negative representations of Muslims by media and governments and the lack of proactive, positive media representation (Hassan, 2010; Hosseini \& Chafic, 2016). However, the impact of this discrimination, vilification, unemployment, and negative media representation on the mental health of Australian Muslim Youth is not well understood and has not been researched as suggested by the findings. Combined with the high percentage of deaths among people aged 15-24 in Australia attributed to suicide (36\%) (Australian Bureau of Statistics, 2017), Australian Muslim adolescents could be a high-risk minority group.
In contrast, studies have found protective factors of religiosity associated with a Muslim adolescent living in Australia. One study found a positive association between Islamic religious practice and life satisfaction (AbuRayya et al., 2016). The impact of these risk and protective factors on the mental health status (i.e., the risk of developing clinically significant psychological problems) of Muslim Australian adolescents is not well understood and researched.

Moreover, only one study on the mental health status of adolescent Muslims living in the United Kingdom (UK) and no studies in Australia were reported. The UK study was an exploratory cross-sectional survey of 14-16 year-olds ( $n=$ 588 ) in two large comprehensive schools (Dabbagh et al., 2012). The Strengths and Difficulties Questionnaire (SDQ) and the Short Moods and Feelings Questionnaire (SMFQ) were used to measure psychological distress. Contrary to predictions, Muslim students had statistically significant lower levels of psychological distress than all other religious groups at the school. In addition, when compared to the SDQ norms for British adolescent populations $(M=$ 10.3; Meltzer et al., 2003), Muslim students overall score of $(M=9.67)$ was lower, indicating the psychological distress levels of British Muslim adolescents was slightly lower than the general UK population.

Despite there being no studies on Muslim adolescents in Australia, several studies have been conducted with the general adolescent population. For example, in a recent study, the 2013-2014 Youth Mind Matters Survey, about $10 \%$ of the sample were found in the clinical range, with a substantial risk of developing clinically significant problems (Lawrence et al., 2015). Risk is defined as the greater probability of consequent clinical risk based on the borderline (top 20\%) and abnormal (top 10\%) clinical cut-off SDQ scores. The borderline SDQ clinical cut-off scores indicated that individuals are at borderline risk of developing clinically significant emotional and behavioural problems. The abnormal clinical cut-off SDQ scores indicated a substantial risk of developing clinically significant social, emotional, behavioural problems. Specifically, the proportion of adolescents with scores in the abnormal clinical range was highest on hyperactivity/inattention (13.9\%), followed by emotional symptoms (10.9\%). In another study, SDQ data was reported on adolescents in routine clinical practice, which shows a greater proportion of individuals in the abnormal range, indicating a substantial risk of developing clinically significant social, emotional and behavioural problems (Brann et al., 2018) when compared to normed Australian SDQ data (Mellor, 2005). 
No studies have examined the risk of developing clinically significant psychological problems for Muslim adolescents in Australia. Considering the risk factors (e.g., discrimination and negative media representation) and protective factors (e.g., religiosity), it is crucial to understand the current levels of social, emotional, and behavioural functioning and psychological distress of Muslim youth to prevent longer-term adverse mental health outcomes and build on the resilience of Muslim youth. As there are Australian norms for the SDQ (Mellor, 2005), data on adolescents in the general population (Lawrence et al., 2015), and routine care (Brann et al., 2018), the first aim of this paper is to determine how does the risk for Australian Muslim adolescents compare with the risk for adolescents in the general population and routine care. The second aim is to ascertain if Australian Muslim adolescents are at a substantially higher risk of developing clinically significant social, emotional, and behavioural problems when compared to the general adolescent population.

As this was the first study that examined the risk of Australian Muslim adolescents developing clinically significant social, emotional, and behavioural problems, it is unclear what the level of risk is. However, based on the UK study where Muslim youth reported lower levels of psychological distress (Dabbagh et al., 2012), it was hypothesised that (1) Australian Muslim adolescents would be at lower risk of developing clinically significant social, emotional and behavioural problems than the general adolescent population, (2) and at lower risk to those in routine care.

\section{Methods}

\section{Design}

A descriptive, cross-sectional, and exploratory survey was utilised to examine the psychological distress levels of Australian Muslim adolescents.

\section{Participants}

Six hundred and thirty-two students (261 males and 371 females) in Year 7-12, aged 12-17, from three Islamic schools in New South Wales (NSW) participated in the study.

\section{Procedure}

Three NSW-based Islamic school principals in demographic areas with a large Muslim population were approached by the Operations Director (AM) of the Lebanese Muslim Association (LMA) and agreed to participate in this research project. Across the three participating schools,
1351 students were asked to complete the survey, from whom 644 responses (48\%) were collected, although 12 responses were invalidated or incomplete, resulting in 632 for the final analysis. From School 1, 317 high school students were approached, and $203(64 \%)$ responded. From School 2, 586 students in their high school campus were asked to complete the questionnaire, of whom $326(56 \%)$ responded. From School 3, 448 high school students were approached, of whom 134 (30\%) completed the questionnaire. The information sheet and consent form to participate and publish were printed and provided to all students to give to their parents. All recruited students were included in the study unless parents provided written consent for their child to opt-out from participation in research. School counsellors and staff were given hard copies of the questionnaire to distribute at roll call and other classes. All students were provided with printed questionnaires and information sheets collected and returned to the LMA by a school representative. The original purpose of the data collection was a grass-roots exploratory study by the local Muslim community trying to understand the mental health needs of their Muslim youth. The director of the LMA approached the lead author (RK) to analyse the data. The collected data used an opt-out consent approach, and the collected data may include responses from students whose parents either did not return the form (as they were happy for their child to take part) or did not see the form for one reason or another. The lead author requested a waiver of consent by the Macquarie University Human Research Ethics Committee to analyse the de-identified data and publish the results, which was approved (Ethics approval number: 52020572614776).

\section{Measures}

The self-report youth version of the Strengths and Difficulties Questionnaire (11-17) (SDQ: Goodman, 2001) was administered. It is a standardised, reliable, and valid questionnaire consisting of 35 items that measure symptoms of psychological distress. The SDQ consists of the following five subscales: (1) Emotional symptoms (e.g., "I am often unhappy, depressed or tearful"); (2) Conduct Problems (e.g., "I get very angry and often lose my temper"); (3) Hyperactivity-Inattention (e.g., "I am restless, I cannot stay still for long"); (4) Peer problems (e.g., "Other children or young people pick on me or bully me"); and (5) Prosocial behaviour (e.g., "I try to be nice to other people. I care about their feelings"). The total difficulties score was calculated by adding all the sub-scales, excluding the prosocial subscale. This current study only utilised the symptom subscales consisting of 25 items, five items per subscale. The clinical cut-off values align with SDQ standard original three-band categorization (http://www.sdqinfo.com/py/sdqinfo/c0.py) 
(Goodman, 2001). The clinical cut-off values of 20, seven, five, seven, six points for the self-rated scales of total difficulties, emotional problems, conduct problems, hyperactivity-inattention, and peer problems were used, respectively. These clinical cut-offs are commonly used in the SDQ literature and recommended in the Australian Mental Health Outcomes and Classification Network SDQ Training Manual (2005), and represent a substantial risk of developing clinically significant psychological problems in the subscale area.

\section{Demographical and SES measures}

A proximal measure of socioeconomic status (SES) was created by matching the self-reported postcodes of students against the socioeconomic index for areas (SEIFA) published by the Australian Bureau of statistics in 2018 (Australian Bureau of Statistics, 2018). Each student was allocated a score of one to five, representing the five quintiles of cumulative postcodes with low (1) or relatively high (5) Index of Relative Socioeconomic Disadvantage (IRSD).

Additional demographics of age, gender, religion, country of birth, and parent's country of birth were also included. These are presented in further detail in Table 1.

\section{Design}

The observed Muslim youth scores in the current study were contrasted against three benchmarks of strengths and difficulties scale scores. Initially, the overall scores from the sample were compared to findings from a large community sample. The Australian benchmark comparative study for the general adolescent population was the Mellor (2005) study which provided normative data for the SDQ in Australia. This study provided baseline data of the psychological distress levels of the general adolescent population. In this way, scores from the Muslim youth are compared against a proximal measure representing the Australian norm. Second, the study scores were contrasted against a range of scores observed within the youth and adolescent treatment-seeking sample. This benchmark represents a threshold of scores from a sample with difficulties and treatment-seeking behaviours. The Australian benchmark comparative study for the adolescent population in routine clinical care was the Brann et al. (2018) study, which provided clinical SDQ data for adolescents in routine clinical care. Third, the percentage of youth and adolescents that scored above the clinical cut-off scores of the SDQ were reported. Individuals whose scores were above the cut-offs are considered to show significant difficulties and a likely need for additional resources and attention. The proportion of individuals with such high
Table 1 Demographic characteristics of respondents

\begin{tabular}{|c|c|c|}
\hline \multirow[t]{2}{*}{ Variable } & \multicolumn{2}{|c|}{$\begin{array}{l}\text { Final Sample } \\
(N=632)\end{array}$} \\
\hline & $n$ & $\%$ \\
\hline \multicolumn{3}{|l|}{ Gender } \\
\hline Male & 261 & $41 \%$ \\
\hline Female & 371 & $59 \%$ \\
\hline \multicolumn{3}{|l|}{ Age } \\
\hline Mean (SD) & 13.8 & \\
\hline Range & $12-1$ & \\
\hline \multicolumn{3}{|l|}{ Age groups for benchmarking purposes } \\
\hline Female $11-13$ y & 174 & $28 \%$ \\
\hline Female 14-17 y (Mellor, 2005) & 194 & $31 \%$ \\
\hline Female 16-17 y (Lawrence et al., 2015) & 58 & $9 \%$ \\
\hline Male $11-13$ y & 121 & $19 \%$ \\
\hline Male 14-17 y (Mellor, 2005) & 132 & $21 \%$ \\
\hline Male 16-17 y (Lawrence et al., 2015) & 35 & $6 \%$ \\
\hline \multicolumn{3}{|l|}{ Religion } \\
\hline Muslim & 629 & $99 \%$ \\
\hline No affiliation/other & 3 & $1 \%$ \\
\hline \multicolumn{3}{|l|}{ Country of birth } \\
\hline Australia & 555 & $88 \%$ \\
\hline Overseas & 77 & $12 \%$ \\
\hline \multicolumn{3}{|l|}{ Parent's country of birth } \\
\hline Australia & 8 & $1 \%$ \\
\hline Overseas & 624 & $99 \%$ \\
\hline \multicolumn{3}{|l|}{ Relative Socioeconomic Disadvantage (IRSD) } \\
\hline Fifth quintile (most advantaged) & 19 & $3 \%$ \\
\hline Fourth quintile (advantaged) & 24 & $4 \%$ \\
\hline Third quintile (average advantage) & 94 & $15 \%$ \\
\hline Second quintile (disadvantaged) & 269 & $42 \%$ \\
\hline First quintile (most disadvantaged) & 194 & $31 \%$ \\
\hline Missing postcode & 32 & $5 \%$ \\
\hline
\end{tabular}

scores was reported for each subgroup of age and gender compared to the Australian norm scores. The Australian benchmark comparative study for a clinical adolescent population was the report on the second Australian child and adolescent survey of mental health and wellbeing, that is, the Young Minds Matter Survey (Lawrence et al., 2015), which used the Goodman (2001) clinical cut-offs to indicate the substantial risk of developing clinical problems by the general adolescent population.

\section{Statistical analyses}

The samples' observed SDQ scores were estimated in three ways. Initially, a series of regression models were conducted to estimate the mean score of the sample. First, the SDQ was represented as total difficulties and sub-scale 


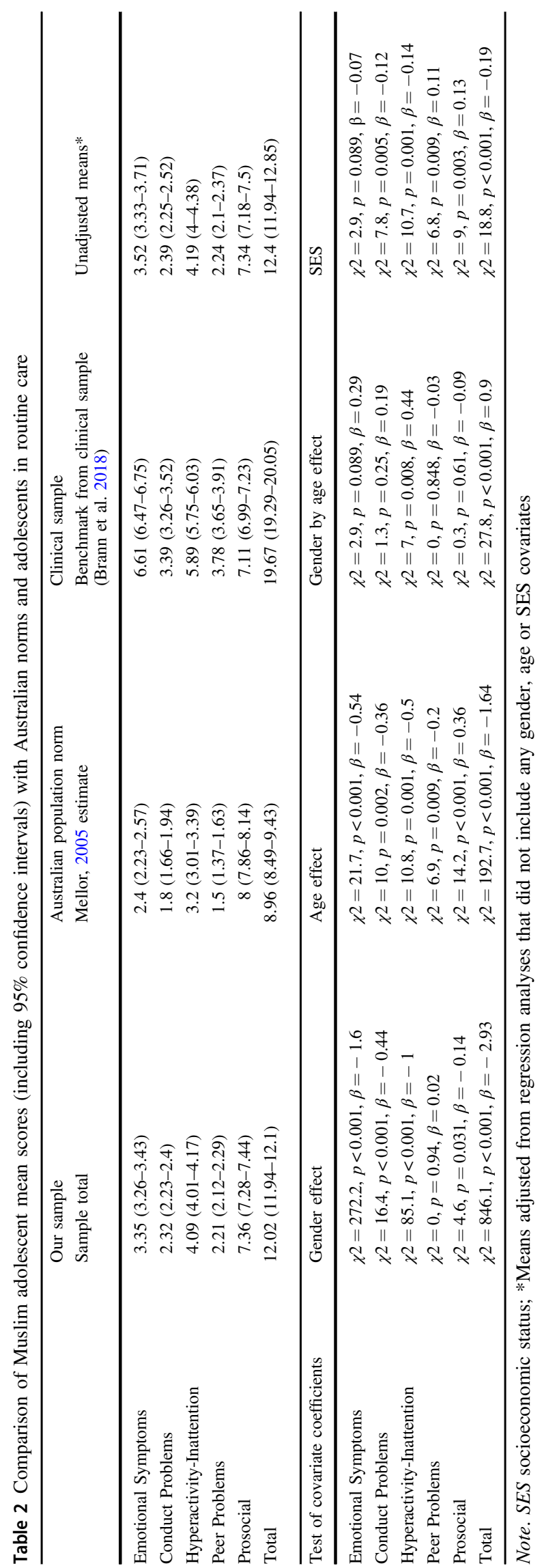

scores, where the total difficulties score was significantly different from any of the benchmarks if the confidence interval of the sample omitted the mean population norm (Vaz et al., 2016). Second, consistent with previous research (e.g., Goodman, 2001; Lawrence et al., 2015; Mellor, 2005) the sample was split into age and gender, denoting that different strengths and difficulties are presented within each level of age and gender (see Table 3). Means for these subgroups were estimates with regression analysis that included gender, age group, and an interaction covariate (see Table 2), previously identified as important covariates (Mellor, 2005). Additional surveyed information such as country of birth, parent's country of birth, socioeconomic status, language spoken at home was also screened as covariates of SDQ scores.

Third, the frequency of individuals who exceed a borderline and abnormal clinical cut-off score were estimated as a proportion of the sample with a high and potentially clinical level of symptoms (Goodman, 2001). The categorisation and analyses of the students with borderline and abnormal scores intend to further represent the borderline and substantial risk of developing clinically significant social, emotional, and behavioural problems amongst the sample, respectively. The frequency of these individuals was estimated with binary logistic regressions that estimated the proportion and confidence interval of the sample above the borderline and abnormal clinical cut-off score. This proportion estimate was then compared to the clinical cut-off scores from the benchmark study (Lawrence et al., 2015) (see Table 4). In this step, the sample's estimate of individuals who exceed a clinical cut-off was adjusted for the effect of variation of age and gender. This adjustment was included to create an average population estimate that can compare the Muslim youth sampled in this survey to youth population-wide estimates reported in a large scale, government-supported benchmarking studies about wellbeing (Lawrence et al., 2015).

In all mean score analyses, the current sample was determined to be significantly higher, or lower, than a benchmarking Australian norm estimate if the 95\% confidence interval of the sample estimate excluded the mean estimate of the Australian norm (Greene et al., 2008). Thus, for example, if a large benchmarking study determined the SDQ population norm to have a mean of 10 , and the current study estimate of SDQ scores had a mean of 12 with a confidence interval of 10.5 and 13.5 , the current study would be considered to exceed the population norm with certainty. That is, the mean of the current sample would be considered to exceed the benchmarking norm more than $95 \%$ of the time if the study was repeated under the same conditions. Amongst binary analyses, Fischer's Z Test for two population proportions statistical tests were used to 
determine if the proportion of students with borderline and abnormal symptoms were significantly higher or lower than the identified benchmarking estimates.

All analyses were performed using the Statistical Package for Social Sciences (SPSS) version 26.0 for Windows (SPSS Inc., Chicago, IL).

\section{Results}

Table 1 shows the demographic characteristics of responders. Table 2 collates the estimates from the regression models that estimate the sample means after adjusting for age, gender, an age and gender interaction, and SES. The adjustment for these effects was statistically significant, implying that the different age and gender groups presented with different strengths and difficulties. For example, Muslim females reported higher mean subscale scores of conduct problems, emotional symptoms, hyperactivity/ inattention, and prosocial behaviours compared to Muslim males and a child's age impacted the means of each of the outcomes. In addition, higher SES was associated with decreased total symptoms, as well as each of the subscales. The adjustment for these covariates did not substantially change the sample mean estimate compared to the unadjusted scores. The remaining considered covariates of country of birth $\left(\chi^{2}=3.021, p=0.963\right)$, parent's country of birth $\left(\chi^{2}=272.2, p<0.001\right)$, and language spoken at home $\left(\chi^{2}=3.744, p=0.711\right)$ were not identified as significant correlates of SDQ scores.

When compared to the Australian norm, the adjusted overall psychological distress levels of Australian Muslim adolescents $(\mathrm{M}=12.02,95 \% \mathrm{CI}[11.94,12.1])$ was significantly greater $(34 \%)$ than adolescents in the general community $(\mathrm{M}=8.96 ; 95 \mathrm{CI} \% \quad[8.49,9.43])$ and significantly lower (39\%) than adolescents in clinical routine care $(M=19.67 ; 95 \%$ CI $[19.29,20.05])$. Figure 1 shows the differences in percentages of Muslim adolescents, Australian normed data (Mellor, 2005), and adolescents in routine clinical care (Brann et al., 2018) respectively.

The comparability of the Australian normed data to the current sample was also made within each age group and gender. Table 3 compares the means by age and gender in the sub-scales of SDQ of Australian Muslim adolescents versus Australian normed data. Results in the table illustrate that the current sample had significantly higher total symptoms scores than the normed data, which were also higher within all subscales but the prosocial scale. In addition, Muslim females in our sample reported higher total symptoms and subscale scores of emotional symptoms, conduct problems, hyperactivity/inattention, and prosocial behaviour when compared to Muslim males.

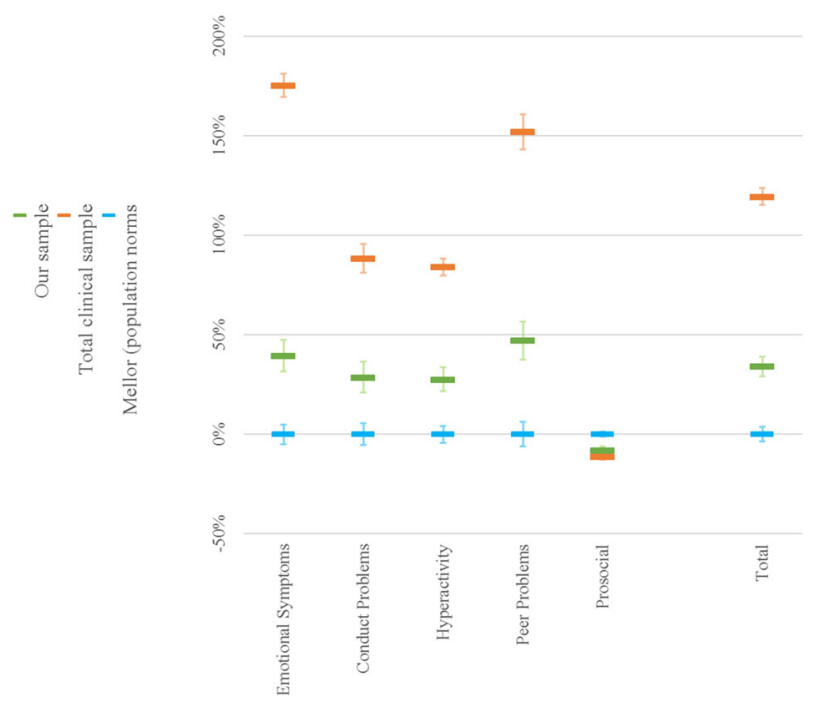

Fig. 1 Comparison of the adjusted psychological distress levels between Muslim adolescents, Australian norms and clinical norms; \% differences convey as relative differences from the benchmarking scores identified from the Mellor (2005) study

Finally, the proportion of individuals who demonstrate social, emotional, and behavioural scores above the population cut-off estimates (i.e., abnormal and borderline range, Goodman, 2001), were categorised and compared to the proportion estimates observed in the Australian national benchmarking estimate. The estimates of the sample total, males and females, and the proportion of individuals above the abnormal clinical cut-off within each subscale and the borderline clinical cut-off for the total sample, males, and females, are presented in Table 4. Table 4 illustrates that, compared to the general adolescent population (Lawrence et al., 2015), the proportion of Muslim youth who scored higher in the borderline range of total difficulties were substantially higher $(29.0 \%$ vs. $23.7 \%, Z=2.57, p=$ 0.010). Muslim youth reported similar levels of severe symptoms and probability of consequential risk of developing clinically significant problems to the Australian benchmark, except for hyperactivity/inattention problems where there is a substantially higher proportion $(18.4 \%$ vs. $13.8 \%, Z=2.70, p=0.007)$. Further, female Muslim adolescents aged 11-15 years reported a significantly higher proportion above the borderline $(31.8 \%$ vs $24 \%$, $Z=2.47, p=0.014)$ and abnormal clinical cut-offs $(14.3 \%$ vs. 9.8\%, $Z=2.23, p=0.026$ ) for total difficulties SDQ scores when compared to age-related peers. In addition, female Muslim adolescents aged 11-15 years reported a significantly higher proportion of females within the abnormal range for emotional symptoms (17.6\% vs $12.6 \%$, $Z=2.24, p=0.025)$ and conduct problems $(11.2 \%$ vs $7.5 \%, Z=2.06, p=0.039$ ), and marginally for hyperactivity $(15.1 \%$ vs $11.4 \%, Z=1.74, p=0.082)$ when compared to age-related peers. 
Table 3 Comparison of Muslim adolescent mean scores for gender and age (including 95\% Confidence Intervals) with Australian norms

\begin{tabular}{|c|c|c|c|c|}
\hline & $\begin{array}{l}\text { Mellor, } 2005 \\
\text { Female } 11-13 \text { y }\end{array}$ & $\begin{array}{l}\text { Our sample } \\
\text { Female 11-13 y }\end{array}$ & $\begin{array}{l}\text { Mellor, } 2005 \\
\text { Female } 14-17 \text { y }\end{array}$ & $\begin{array}{l}\text { Our sample } \\
\text { Female } 14-17 \text { y }\end{array}$ \\
\hline Emotional symptoms & $2.6(2.26-2.94)$ & $3.78(3.63-3.93)$ & $2.85(2.54-3.16)$ & $4.32(4.18-4.47)$ \\
\hline Conduct problems & $1.31(1.07-1.56)$ & $2.3(2.15-2.46)$ & $1.71(1.47-1.95)$ & $2.67(2.52-2.81)$ \\
\hline Hyperactivity & $2.63(2.27-2.99)$ & $4.23(4.07-4.38)$ & $3.13(2.78-3.48)$ & $4.72(4.58-4.87)$ \\
\hline Peer problems & $1.4(1.14-1.66)$ & $2.1(1.95-2.25)$ & $1.38(1.15-1.61)$ & $2.31(2.16-2.45)$ \\
\hline Prosocial & $8.56(8.33-8.79)$ & $7.63(7.48-7.78)$ & $8.36(8.1-8.62)$ & $7.27(7.13-7.42)$ \\
\hline \multirow[t]{3}{*}{ Total } & $7.96(6.97-8.95)$ & $12.44(12.29-12.6)$ & $9.08(8.3-9.86)$ & $14.08(13.94-14.23)$ \\
\hline & Mellor, 2005 & & Mellor, 2005 & \\
\hline & Male $11-13$ yrs & Male $11-13$ yrs & Male $14-17$ yrs & Male $14-17$ yrs \\
\hline Emotional symptoms & $1.99(1.68-2.3)$ & $2.52(2.33-2.71)$ & $2.07(1.7-2.44)$ & $2.77(2.59-2.95)$ \\
\hline Conduct problems & $1.96(1.67-2.25)$ & $2.06(1.88-2.25)$ & $2.38(2.03-2.73)$ & $2.23(2.06-2.4)$ \\
\hline Hyperactivity & $3.15(2.79-3.51)$ & $3.67(3.49-3.86)$ & $4.01(3.58-4.44)$ & $3.73(3.56-3.9)$ \\
\hline Peer problems & $1.7(1.44-1.96)$ & $2.09(1.9-2.28)$ & $1.62(1.33-1.91)$ & $2.33(2.16-2.5)$ \\
\hline Prosocial & $7.75(7.45-8.05)$ & $7.41(7.22-7.59)$ & $7.25(6.93-7.57)$ & $7.13(6.96-7.31)$ \\
\hline Total & $8.8(7.92-9.68)$ & $10.41(10.22-10.6)$ & $10.12(9.03-11.21)$ & $11.15(10.97-11.32)$ \\
\hline
\end{tabular}

\section{Discussion}

Hypothesis 1 was not supported with $18.4 \%$ of Australian Muslim adolescents scoring in the abnormal range for hyperactivity/inattention compared to $13.8 \%$ in the general community sample, indicating a higher substantial risk of developing clinically significant hyperactivity/inattention problems when compared to the general adolescent community data, but not for emotional symptoms, peer and conduct problems, and total difficulties. In addition, 29\% of Australian Muslim adolescents in the current study reported scoring in the borderline range compared to $23.7 \%$, indicating a significantly higher borderline risk of having clinically significant social, emotional, and behavioural problems. Another important finding was that Muslim females aged 11-15 years reported significantly higher proportions in the abnormal (14.3\% vs. 9.8\%) and borderline ranges (31.8\% vs. $24 \%$ ) for total difficulties, emotional symptoms (17.6\% vs. $12.6 \%)$, conduct problems ( $11.2 \%$ vs. $7.5 \%)$, and marginally hyperactivity/ inattention (15.1\% vs. $11.4 \%)$, indicating a substantial risk of developing clinically significant mental health problems, particularly emotional and conduct problems. No other group, younger and older males or older Muslim females, differed from the general community sample on any scale, including total difficulties and hyperactivity/ inattention. The current study's findings differed from the UK study, which reported Muslim youth reported lower psychological distress levels than the general community sample (Dabbagh et al., 2012). This lower level may be due to British Muslim youth having more significant protective factors of religiosity and community belonging than the Australian Muslim youth. Still, this hypothesis would need to be confirmed by future research.

Hypothesis 2 was not able to be supported as calculating risk was not possible as proportions of individuals in the borderline and abnormal range were not provided in the routine care study (Brann et al., 2018). However, Australian Muslim adolescents scored significant lower mean scores (39\% less than SDQ scores in routine care and see Fig. 1), suggesting a probable reduced risk of developing mental health problems, but this would need to be confirmed with future research that measures proportions of adolescents in routine care that are above the borderline and abnormal clinical cut-offs of the SDQ.

Looking at the total difficulties SDQ score, this risk for Australian Muslim adolescents is not substantially higher than adolescents in the general community. Both groups report similar clinical levels of psychological distress and a similar substantial risk of developing clinically significant problems. About 1 in 10 (11.9\%) Australian Muslim adolescents sampled in this study reported a substantial risk of developing clinically significant problems. This risk is similar to the results of the 2013-2014 Young Minds Matter Survey (Lawrence et al., 2015), where one in ten $(10 \%)$ adolescents in the general population reported being at substantial risk of developing clinically significant problems on the SDQ (Lawrence et al., 2015). However, the proportion of Muslim young people with abnormal scores was highest on the hyperactivity scale, followed by the emotional symptoms scale ( $18.4 \%$ and $12.4 \%$, respectively), which is consistent with the results of the Young Minds Matter Survey where hyperactivity $(13.8 \%)$ and emotional problems (10.9\%) 


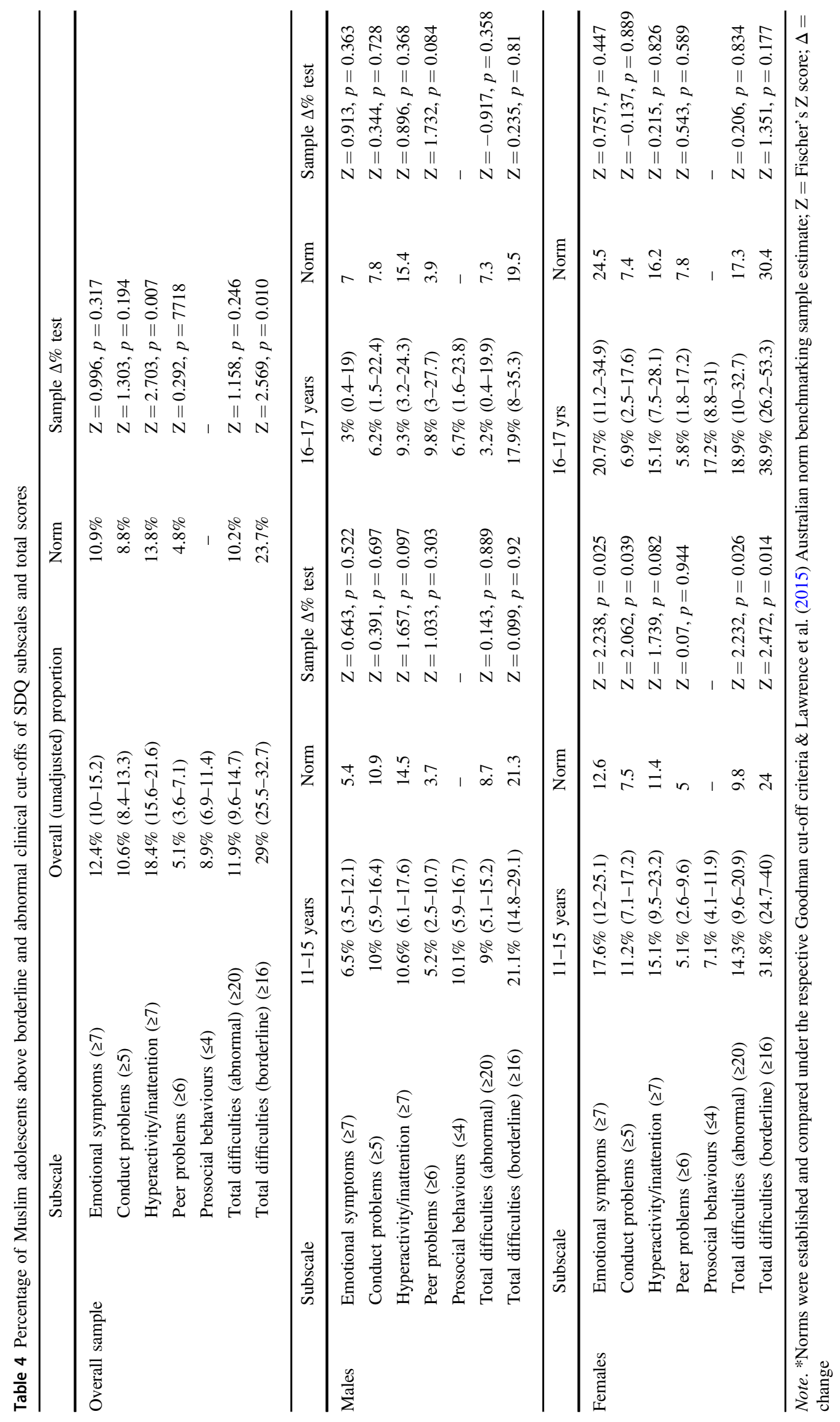


were the highest scores. Muslim adolescents reported more significant difficulties in hyperactivity $(18.4 \%$ vs. $13.8 \%)$ compared to the general adolescent population. However, this difference is explained by the Muslim females' subgroup aged $11-15$ years old.

A gender subgroup analysis (see Table 4) found that Muslim females aged 11-15 years scored higher on emotional symptoms, conduct problems, and marginally hyperactivity and were the leading contributing group to the difference with the general community sample. The following reasons explain the higher risk of developing clinically significant problems of emotional and behavioural symptoms of Muslim females aged 11-15 years in the current study: First, the high percentage of children from first-generation immigrants are at higher risk of problem behaviours when compared to children from the host culture (Flink et al., 2012). Second, Muslim females aged 11-15 may have lower levels of ethnic identity when compared to Muslim males (11-17 years) and older Muslim females (16-17 years). A longitudinal examination of early adolescence ethnic identity trajectories found the following six latent class trajectories in ethnic identity levels (1) growth (2) high levels remained stable (3) moderate decreases (4) significant declines (5) significant increases, and (6) low levels remained stable (Huang \& Stormshak, 2011). Muslim females aged 11-15 years may report low levels remaining stable or significant decreases in ethnic identity levels and cannot mitigate the risks associated with their reported experience of vilification and discrimination. Future research would need to explore the impact of the protective factor of ethnic identity in mitigating the risk factors of vilification and discrimination for Muslim females aged 11-15 to understand why they differ from younger and older males and older Muslim females. Another reason why similar differences were not found for Muslim females aged 16-17 years may be related to an underpowered sample of the 16-17 years subgroup $(n=59)$ compared to the $11-15$ years subgroup $(n=312)$. Future research on gender differences in Muslim adolescents to unpack the interplay of protective and risk factors is required, and a larger replication of our study that recruits more Muslim females aged 16-17 years.

Muslim females were found to score higher on all scales when compared to Muslim males, except for peer problems. Consistent with previous research (Lawrence et al., 2015), Muslim female adolescents are at higher risk of developing clinically significant emotional problems when compared to Muslim male adolescents. However, an unexpected finding was that Muslim female adolescents were at a higher implied risk of developing clinical hyperactivity and conduct problems when compared to Muslim males. This unexpected finding may be explained because girls exposed to trauma reported more significant conduct disorder
(Bernhard et al., 2018). However, trauma rates between Muslim boys and girls have not been researched. Also, Muslim female adolescents have been reported to be subject to higher rates of vilification and discrimination when compared to Muslim male adolescents because they wear the hijab, making them more easily identifiable and more vulnerable targets for discrimination and vilification (Ferdinand et al., 2015; Jasperse et al., 2012). For example, a recent exploratory meta-analysis over the last 10 years found that Muslim women wearing the hijab were $40 \%$ less likely to be employed than Muslim women not wearing the hijab (Ahmed \& Gorey, 2021). Finally, another reason could be the underreporting of Muslim males for conduct problems to protect family reputation in the community, a common cultural factor in Islamic collectivistic cultures (Gearing et al., 2012; Shalhoub-Kevorkian, 2005).

An important finding was that other than Muslim females aged 11-15 years, younger and older males and older females were at a similar substantial risk of developing clinically significant emotion symptoms ( $12.4 \%$ vs. $10.9 \%)$, conduct problems $(10.6 \%$ vs. $8.8 \%)$ and peer problems $(5.1 \%$ vs. $4.8 \%)$ in the abnormal range when compared to the general adolescent population. Here, the interplay between protective and risk factors may clarify the younger and older males and older females. On the one hand, the experience of discrimination and negative media representation may increase the risk of Muslim youth developing moderate clinically significant emotional problems. On the other hand, the protective factor of religious practices and higher levels of ethnic identity may help Muslim youth manage emotional problems and reduce the risk of increasing from moderate to severe. Future research would need to confirm this hypothesis.

The clinical implications of this present study reflect that, similar to adolescents in the general community, some Muslim adolescents (i.e., especially Muslim females aged 11-15 years) are at risk of developing clinically significant problems and may need support. Several evidence-based interventions and prevention approaches exist for various adolescent disorders that could be used with the Australian Muslim adolescent population. They include evidencebased outpatient psychosocial treatment provided by Child and Adolescent Mental Health Services that reduce symptoms associated with disorders, family-focused treatment, and integrated school- and community-based approaches (Hoagwood et al., 2001). A recent meta-analysis examining the effects of youth psychological therapy over five decades found that youth-focused behavioural therapies (including cognitive behaviour therapy) to families, caregivers, or individuals had similar robust effects across youth, parent, and teacher self-reports (Weisz et al., 2017). Furthermore, these effects did not differ when comparing Caucasian versus minority samples, although more diverse samples 
were needed. Thus, youth-focused behavioural therapies, such as Cognitive Behavioural Therapy, could be offered via school-based or community-based programs to Muslim youth and their families to reduce their social, emotional, and behavioural problems.

However, reflecting the gap in the literature review of the current study concerning protective factors and mental health treatment, it is not clear what type of treatment or preventative approaches are needed for the mental health of Australian Muslim adolescents. Although youth-focused behavioural therapies, such as CBT, hold promise for Australian Muslim youth, future research will need to conduct a collaborative approach with Australian Muslim communities and schools to develop and evaluate the acceptability and effectiveness of the youth-focused behavioural therapies.

The limitations of the current study were methodological. First, the generalising of the results must be interpreted with caution as the present study sampled only 3 of 46 Islamic schools in Australia. Second, the reliance on self-report and lack of use of parent and teacher reports on the SDQ and other measures limits the extent to which identified symptoms are corroborated. A third limitation was the lack of the use of a diagnostic clinical interview to determine the mental health conditions reported by Muslim adolescents. Fourth, other factors such as adolescents' experience of bullying and health-risk behaviours (e.g., substance use and problem eating behaviours) could have been assessed. Finally, other limitations are the threats to internal and external validity. One example of a threat to the internal validity is the sample bias of the study, that is, the passive consent process that relied on students to provide consent forms to parents and further suggests the need to interpret data obtained with caution. Other threats to internal validity included: (1) the lack of data collection on factors that could influence adolescent mental health, such as peer relationships, family relationships, school and community factors; (2) data on Muslim adolescents attending other/public schools were not collected. Notwithstanding these limitations, covariates such as country of birth, parent's country of birth, SES, and language spoken at home were explored and found to be non-significant and not threats to external validity. Future research could control for these threats to internal and external validity and replicate the current study across several Islamic schools in Australia to include a larger sample, parent and teacher self-reports, a structured diagnostic clinical interview, and questions to assess factors that could influence adolescent mental health such as peer relationships, family relationships, school factors, and community factors. Nevertheless, this is the first study that examines the psychological distress levels of Australian Muslim adolescents and provides a baseline for future research to build on.
In conclusion, Australian Muslim females aged 11-15 years are at greater substantial risk of developing clinical problems of emotional symptoms and conduct problems compared to the adolescents in the general community. Left untreated, this could have an array of adverse life and health outcomes. Therefore, developing and providing Islamic community-driven culturally and religiously congruent mental health resources and outreach services are critical for mitigating these risks among Muslim adolescents in Australia, particularly for females aged 11-15 years.

\section{Data Availability}

The data supporting the results and analyses can be found with the lead author. Access to de-identified data will be provided for the purpose of verifying the findings presented in the current study. Access will be provided to researchers, subject to a formal written request, the generation of a methodologically sound research protocol, the establishment of appropriate data governance, and the approval of an independent and recognised Human Research Ethics Committee.

Acknowledgements The contribution of the principals and staff from the schools, and the members of the Lebanese Muslim Association who assisted in the approval and collecting of data is gratefully acknowledged. Also, we would like to acknowledge Sydney Local Health District for their support of this project.

Author Contributions R.K. designed the study, conducted literature review, interpreted the data, and draughted the manuscript. E.K. reviewed the design of the study, conducted analyses and draughted the analysis sections of the manuscript. A.M., C.G., N.C. conceived the study, reviewed the design, analysis, interpretation of data and the manuscript. All authors have contributed to, read and approved the manuscript.

Funding Open Access funding enabled and organized by CAUL and its Member Institutions.

\section{Compliance with Ethical Standards}

Conflict of Interest The authors declare no competing interests.

Ethical Approval The questionnaire and methodology for this study was approved by the Human Research Ethics committee of Macquarie University (Ethics approval number: 52020572614776).

Consent to Participate and Publish The information sheet and consent form to participate and publish were printed and provided to all students to give to their parents, whom provide written consent if they did not want their child to participate in the study. School counsellors and staff were given hard copies of the questionnaire to distribute at roll call and other classes. All students were provided with printed questionnaires and information sheets, which were collected and returned to the LMA by a school representative. The original purpose of the data collection was a grass-root exploratory study by the local Muslim community trying to understand the mental health needs of their 
Muslim youth. The director of the LMA approached the lead author (RK) to analyse the data. As the collected data used an opt-out consent approach, and the collected data may include responses from students whose parents either did not return the form (as they were happy for their child to take part), or who did not see the form for one reason or another. The lead author requested a waiver of consent by the Macquarie University Human Research Ethics Committee in order to analyse the de-identified data and publish the results, which was approved.

Publisher's note Springer Nature remains neutral with regard to jurisdictional claims in published maps and institutional affiliations.

Open Access This article is licensed under a Creative Commons Attribution 4.0 International License, which permits use, sharing, adaptation, distribution and reproduction in any medium or format, as long as you give appropriate credit to the original author(s) and the source, provide a link to the Creative Commons license, and indicate if changes were made. The images or other third party material in this article are included in the article's Creative Commons license, unless indicated otherwise in a credit line to the material. If material is not included in the article's Creative Commons license and your intended use is not permitted by statutory regulation or exceeds the permitted use, you will need to obtain permission directly from the copyright holder. To view a copy of this license, visit http://creativecommons. org/licenses/by/4.0/.

\section{References}

Abu-Rayya, H. M., Almoty, S., White, F. A., \& Abu-Rayya, M. H. (2016). The interconnection between Islamic religiosity and deviancy among Australian Muslim youth: A partial mediation role of life satisfaction. The International Journal for the Psychology of Religion, 26(4), 337-347. https://doi.org/10.1080/ 10508619.2016.1157720.

Ahmed, S., \& Gorey, K. M. (2021). Employment discrimination faced by Muslim women wearing the hijab: Exploratory meta-analysis. Journal of Ethnic \& Cultural Diversity in Social Work, 1-9. https://doi.org/10.1080/15313204.2020.1870601.

Australian Bureau of Statistics. (2016). 2071.0 - Census Population and Housing: Reflecting Australia - Stories from the Census, 2016 - Religion in Australia. Retrieved March 2, from https://w eb.archive.org/web/20170919010053/http://www.abs.gov.au/a usstats/abs@.nsf/Lookup/by\%20Subject/2071.0 2016 Main\% 20Features Religion\%20Data\%20Summary 25

Australian Bureau of Statistics. (2017). 3303.0 - Causes of Death, Australia, 2017. Retrieved March 2, from https://www.abs.gov. au/ausstats/abs@.nsf/Lookup/by\%20Subject/3303.0 2017 Main $\% 20$ Features Intentional\%20self-harm,\%20key\%20chara cteristics $\sim 3$

Australian Bureau of Statistics. (2018). Census of Population and Housing: Socio-Economic Indexes forAreas (SEIFA), Australia, 2016. Catalogue No. 2033.0.55.001. Retrieved June 26, from http://www.abs.gov.au/ausstats/abs@.nsf/mf/2033.0.55.001. Accessed

Australian Mental Health Outcomes and Classification Network. (2005). Strengths and difficulties questionnaire: Training manual. NSW Institute of Psychiatry. Retrieved October 8, from https://www.amhocn.org/sites/default/files/publication_files/sdq_ manual_0.pdf

Bernhard, A., Martinelli, A., Ackermann, K., Saure, D., \& Freitag, C. M. (2018). Association of trauma, posttraumatic stress disorder and conduct disorder: A systematic review and meta-analysis
[Neuroses \& Anxiety Disorders 3215]. Neuroscience and Biobehavioral Reviews, 91, 153-169. https://doi.org/10.1016/j. neubiorev.2016.12.019.

Brann, P., Lethbridge, M. J., \& Mildred, H. (2018). The young adult strengths and difficulties questionnaire (SDQ) in routine clinical practice. Psychiatry Research, 264, 340-345. https://doi.org/10. 1016/j.psychres.2018.03.001.

Cheref, S., Talavera, D., \& Walker, R. L. (2019). Perceived discrimination and suicide ideation: Moderating roles of anxiety symptoms and ethnic identity among Asian American, African American, and Hispanic emerging adults. Suicide and Life-Threatening Behavior, 49(3), 665-677. https://doi.org/10.1111/sltb.12467.

Dabbagh, N., Johnson, S., King, M., \& Blizard, R. (2012). Muslim adolescent mental health in the UK: An exploratory crosssectional school survey. International Journal of Culture and Mental Health, 5(3), 202-218. https://doi.org/10.1080/17542863. 2011.594246.

Ferdinand, A. S., Paradies, Y., \& Kelaher, M. (2015). Mental health impacts of racial discrimination in Australian culturally and linguistically diverse communities: A cross-sectional survey. BMC Public Health, 15(1), 401. https://doi.org/10.1186/s12889-015-1661-1.

Flink, I. J., Jansen, P. W., Beirens, T. M., Tiemeier, H., van IJzendoorn, M. H., Jaddoe, V. W., Hofman, A., \& Raat, H. (2012). Differences in problem behaviour among ethnic minority and majority preschoolers in the Netherlands and the role of family functioning and parenting factors as mediators: The Generation $\mathrm{R}$ Study. BMC Public Health, 12(1), 1092. https://doi.org/10.1186/ 1471-2458-12-1092.

Gearing, R. E., Schwalbe, C. S., MacKenzie, M. J., Brewer, K. B., Ibrahim, R. W., Olimat, H. S., Al-Makhamreh, S. S., Mian, I., \& Al-Krenawi, A. (2012). Adaptation and translation of mental health interventions in Middle Eastern Arab countries: A systematic review of barriers to and strategies for effective treatment implementation. International Journal of Social Psychiatry, 59 (7), 671-681. https://doi.org/10.1177/0020764012452349.

Goodman, R. (2001). Psychometric properties of the Strengths and Difficulties Questionnaire. Journal of the American Academy of Child and Adolescent Psychiatry, 40(11), 1337-1345. https://doi. org/10.1097/00004583-200111000-00015.

Greene, C. J., Morland, L. A., Durkalski, V. L., \& Frueh, B. C. (2008). Noninferiority and equivalence designs: Issues and implications for mental health research. Journal of Traumatic Stress, 21(5), 433-439. https://doi.org/10.1002/jts.20367. Oct.

Hassan, R. (2010). Socio-economic marginalization of Muslims in contemporary Australia: Implications for social inclusion. Journal of Muslim Minority Affairs, 30(4), 575-584. https://doi.org/ 10.1080/13602004.2010.533455.

Hoagwood, K., Burns, B. J., Kiser, L., Ringeisen, H., \& Schoenwald, S. K. (2001). Evidence-based practice in child and adolescent mental health services. Psychiatric Services, 52(9), 1179-1189. https://doi.org/10.1176/appi.ps.52.9.1179.

Hosseini, S. A. H., \& Chafic, W. (2016). Muslim youth identity: A review of Australian research since the 1980s SSRN. https://doi. org/10.2139/ssrn.2711732.

Huang, C. Y., \& Stormshak, E. A. (2011). A longitudinal examination of early adolescence ethnic identity trajectories. Cultural Diversity \& Ethnic Minority Psychology, 17(3), 261-270. https://doi. org/10.1037/a0023882.

Jasperse, M., Ward, C., \& Jose, P. E. (2012). Identity, perceived religious discrimination, and psychological well-being in Muslim immigrant women. Applied Psychology, 61(2), 250-271. https:// doi.org/10.1111/j.1464-0597.2011.00467.x.

Kim, J. H., Kim, J. Y., Lee, J., Jeong, G. H., Lee, E., Lee, S., Lee, K. H., Kronbichler, A., Stubbs, B., Solmi, M., Koyanagi, A., Hong, S. H., Dragioti, E., Jacob, L., Brunoni, A. R., Carvalho, A. F., Radua, J., Thompson, T., Smith, L., Oh, H., Yang, L., Grabovac, 
I., Schuch, F., Fornaro, M., Stickley, A., Rais, T. B., Salazar de Pablo, G., Shin, J. I., \& Fusar-Poli, P. (2020). Environmental risk factors, protective factors, and peripheral biomarkers for ADHD: An umbrella review. The Lancet Psychiatry, 7(11), 955-970. https://doi.org/10.1016/S2215-0366(20)30312-6.

Kim, J. Y., Son, M. J., Son, C. Y., Radua, J., Eisenhut, M., Gressier, F., Koyanagi, A., Carvalho, A. F., Stubbs, B., Solmi, M., Rais, T. B., Lee, K. H., Kronbichler, A., Dragioti, E., Shin, J. I., \& FusarPoli, P. (2019). Environmental risk factors and biomarkers for autism spectrum disorder: An umbrella review of the evidence. The Lancet Psychiatry, 6(7), 590-600. https://doi.org/10.1016/ S2215-0366(19)30181-6.

Lawrence, D., Johnson, S., Hafekost, J., Boterhoven de Haan, K., Sawyer, M., Ainley, J., \& Zubrick, S. R. (2015). The mental health of children and adolescents: Report on the second Australian child and adolescent survey of mental health and wellbeing. Retrieved from http://www.health.gov.au/internet/main/publishing.nsf/Content/ 9DA8CA21306FE6EDCA257E2700016945/\$File/child2.pdf

Mellor, D. (2005). Normative data for the strengths and difficulties questionnaire in Australia. Australian Psychologist, 40(3), 215-222. https://doi.org/10.1080/00050060500243475.

Meltzer, H., Gatward, R., Goodman, R., \& Ford, T. (2003). Mental health of children and adolescents in Great Britain. International Review of Psychiatry, 15(1-2), 185-187. https://doi.org/10.1080/ 0954026021000046155.

Paus, T., Keshavan, M., \& Giedd, J. N. (2008). Why do many psychiatric disorders emerge during adolescence? Nature Reviews. Neuroscience, 9(12), 947-957. https://doi.org/10.1038/nrn2513.

Priest, N., Paradies, Y., Trenerry, B., Truong, M., Karlsen, S., \& Kelly, Y. (2013). A systematic review of studies examining the relationship between reported racism and health and wellbeing for children and young people. Social Science and Medicine, 95, 115-127. https://doi.org/10.1016/j.socscimed.2012.11.031.
Shalhoub-Kevorkian, N. (2005). Disclosure of child abuse in conflict areas. Violence Against Women, 11(10), 1263-1291. https://doi. org/10.1177/1077801205280180.

Solmi, M., Dragioti, E., Arango, C., Radua, J., Ostinelli, E., Kilic, O., Yilmaz, U. E., Yalcinay-İnan, M., Soares, F. C., Mariano, L., Mosillo, P., Cortese, S., Correll, C. U., Carvalho, A. F., Shin, J. I., \& Fusar-Poli, P. (2021). Risk and protective factors for mental disorders with onset in childhood/adolescence: An umbrella review of published meta-analyses of observational longitudinal studies. Neuroscience and Biobehavioral Reviews, 120, 565-573. https://doi.org/10.1016/j.neubiorev.2020.09.002.

Vaz, S., Cordier, R., Boyes, M., Parsons, R., Joosten, A., Ciccarelli, M., Falkmer, M., \& Falkmer, T. (2016). Is using the Strengths and Difficulties Questionnaire in a community sample the optimal way to assess mental health functioning? PloS ONE, 11(1), 1-24. https://doi.org/10.1371/journal.pone.0144039.

Walker, R., Francis, D., Brody, G., Simons, R., Cutrona, C., \& Gibbons, F. (2017). A longitudinal study of racial discrimination and risk for death ideation in African American youth. Suicide and Life-Threatening Behavior, 47(1), 86-102. https://doi.org/10. $1111 /$ sltb.12251.

Walker, R. L., Wingate, L. R., Obasi, E. M., \& Joiner, T. E. (2008). An empirical investigation of acculturative stress and ethnic Identity as moderators for Depression and Suicidal Ideation in college students. Cultural Diversity \& Ethnic Minority Psychology, 14(1), 75-82. https://doi.org/10.1037/1099-9809.14.1.75.

Weisz, J. R., Kuppens, S., Ng, M. Y., Eckshtain, D., Ugueto, A. M., Vaughn-Coaxum, R., Jensen-Doss, A., Hawley, K. M., Krumholz Marchette, L. S., Chu, B. C., Weersing, V. R., \& Fordwood, S. R. (2017). What five decades of research tells us about the effects of youth psychological therapy: A multilevel meta-analysis and implications for science and practice. American Psychologist, 72(2), 79-117. https://doi.org/10.1037/a0040360. 